\title{
The Impact of Big Data on Electronic Commerce in Profit Organisations
} in Saudi Arabia

\author{
Bader A. Alyoubi ${ }^{1}$ \\ ${ }^{1}$ Department of Management Information Systems, College of Business, University of Jeddah, Jeddah, Saudi Arabia \\ Correspondence: Bader A. Alyoubi, Department of Management Information Systems, College of Business, \\ University of Jeddah, Jeddah, Saudi Arabia.
}

Received: October 24, 2019

Accepted: November 15, 2019

Online Published: December 22, 2019

doi:10.5430/rwe.v10n4p106

URL: https://doi.org/10.5430/rwe.v10n4p106

\begin{abstract}
Big Data is gaining rapid popularity in e-commerce sector across the globe. There is a general consensus among experts that Saudi organisations are late in adopting new technologies. It is generally believed that the lack of research in latest technologies that are specific to Saudi Arabia that is culturally, socially, and economically different from the West, is one of the key factors for the delay in technology adoption in Saudi Arabia. Hence, to fill this gap to a certain extent and create awareness about Big Data technology, the primary goal of this research was to identify the impact of Big Data on e-commerce organisations in Saudi Arabia. Internet has changed the business environment of Saudi Arabia too. E-commerce is set for achieving new heights due to latest technological advancements. A qualitative research approach was used by conducting interviews with highly experienced professional to gather primary data. Using multiple sources of evidence, this research found out that traditional databases are not capable of handling massive data. Big Data is a promising technology that can be adopted by e-commerce companies in Saudi Arabia. Big Data's predictive analytics will certainly help e-commerce companies to gain better insight of the consumer behaviour and thus offer customised products and services. The key finding of this research is that Big Data has a significant impact in e-commerce organisations in Saudi Arabia on various verticals like customer retention, inventory management, product customisation, and fraud detection.
\end{abstract}

Keywords: big data, e-commerce, Saudi Arabia, social media

\section{Introduction}

Chen et al. (2014) argued that Internet technology has transformed the way of doing business drastically. They added that latest technological advancements are the driving force behind the rapid growth of e-commerce industry. E-commerce organisations are making the customer buying experience more interactive and engaging. Almosa (2011) rightly argued that understanding the consumer behaviour is one of the biggest challenges faced by the businesses globally. Mikalef et al. (2018) substantiated that view and added that several factors such as diverse cultural backgrounds, socio-economic factors, demography, etc., have made the understanding of consumer behaviour more complicated. Wamba et al. (2015) stated that catering to the needs of individual consumer is the key to stay sustainable in this highly competitive market.

Raguseo and Vitari (2018) reported that Big Data technology is gaining rapid popularity especially amongst the e-commerce organisations. Raguseo and Vitari (2018) reported that Big Data technology's ability to handle and process massive amounts of data with speed and secured way are the key reasons for its popularity. Manyika et al. (2011) observed that most of the organisations in Saudi Arabia are late in implementing new technologies. We agree with the counter-argument by Alkhunaizan and Love (2013) who stated that lack of research that are specific to Saudi Arabia is one of the main reasons behind the delay in adopting new technologies by the Saudi organisations. Therefore, there is an urgent need of evaluation of new technologies that are specific to Saudi Arabia's business environment. This would help Saudi organisations gain better insight about latest technologies. In this context, this research becomes more relevant and important as this work is aimed at fulfilling the gap in research by identifying the impact Big Data technology specifically on for-profit e-commerce Saudi organisations. This research critically evaluates the e-commerce sector through the prism of social media and Big Data. The following sections examine the challenges, opportunities, and the impact of Big Data on e-commerce organisations in Saudi Arabia through various literature, journals, and articles from several experts and scholars. This research then concludes with findings 
and analysis based on the primary data gathered through qualitative interviews with highly experienced professionals and using literature research as the secondary data to substantiate the findings with multiple sources of evidence.

\section{Big Data, Social Media, and E-commerce}

Raguseo and Vitari (2018) stated that Big Data is generally defined using its characteristics: volume, velocity, and variety. Volume refers to size of the data, velocity represents the speed at which the data is captured, and variety implies type of datasets that could be structured, unstructured, or semi-structured. Internet technology has enabled the free flow of information in huge volumes from various sources. In this era of social media, no business can ignore the power of information emanating from social media sites such as Twitter, Facebook, WhatsApp, Instagram, and lot more (Barlow, 2013). We concur with the views of AlGhamdi et al. (2011) who reported that due to massive increase in information flow from various sources, traditional databases do not have the ability to deal with large amounts of data that are heterogeneous in nature. This situation led to the emergence of Big Data technology that offers the mechanism to handle large data by capturing, processing, and interpreting in an effective way.

Social media generates lots of data every day that are of high speed, high volume, and variety. Al-Shohaib et al. (2009) strongly believed that social media is a powerful tool that can be used to direct customers towards a product, offers, or just to stay connected with the customers and build and interactive relationship with the customers. Raguseo and Vitari (2018) stressed the importance of e-commerce businesses having an active social media presence. They further added that sometimes it could be difficult to measure returns from social networks. However, they argued that it certainly helps in building brand loyalty and creating a sense of community.

Barlow (2013) defined e-commerce as buying, selling exchanging, transferring products or services using Internet as a medium. With the higher penetration rate of Internet globally, people can shop wherever they want and whenever they want using devices such as computer, laptop, smartphones, etc. With e-commerce, customers can browse through a large database of products and services and can also compare the products. Saudi Arabia is also not behind in embracing e-commerce and transaction value is growing year after year (Akter and Wamba, 2016).

\section{Challenges of E-commerce Organisations in Saudi Arabia}

Raguseo and Vitari (2018) conducted a detailed study on challenges in adopting Big Data by several countries that are culturally, socially, economically and demographically different from each other. They concluded that that challenges faced by countries could be specific to a certain country or can share similar challenges with other counties. Therefore, we are of the view that Big Data should be thoroughly evaluated before adopting it. AlGhamdi et el. (2011) highlighted some of the challenges faced by e-commerce organisations in Saudi Arabia. They conducted the study in 2011 and the challenges identified included government support, high speed Internet, online payment facilities, competitive pricing and consumer awareness. Similarly, Ahmad and Agrawal (2012) conducted a study in 2012 about barriers in implementing e-commerce in Saudi Arabia and identified six barriers; cultural aspects, lack of professionals, logistics, lack of technology, fear of taking risk and fear of failure. We concur with the findings of these studies, however, we believe that a lot has changed since those studies and most of the challenges raised by them have been addressed. Figure 1 below substantiates this view that illustrates the massive increase in Internet penetration rate in Saudi Arabia. From Figure 2, that depicts the transaction values of digital payments and it is estimated to double by 2023 . 


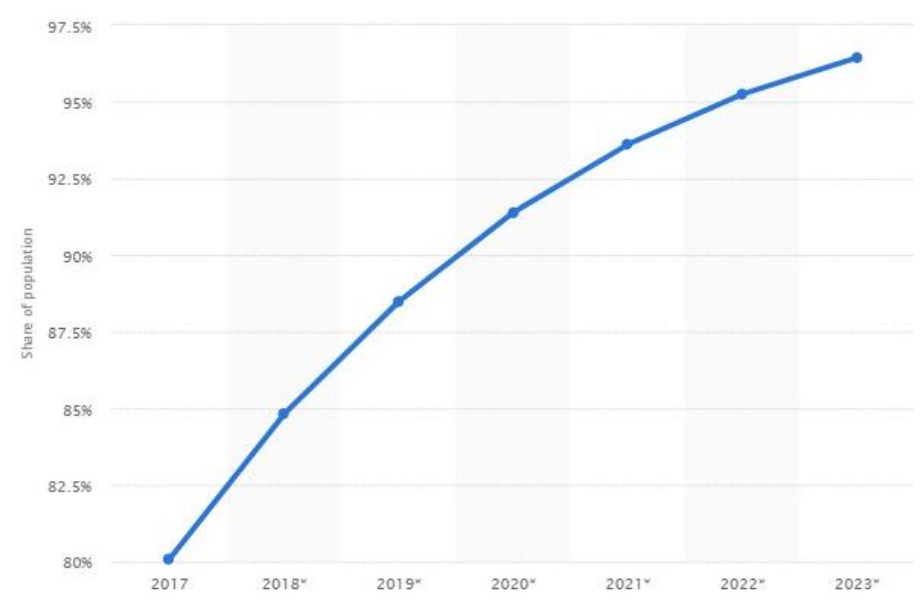

Figure 1. Internet penetration rate in Saudi Arabia (Statista, 2019)

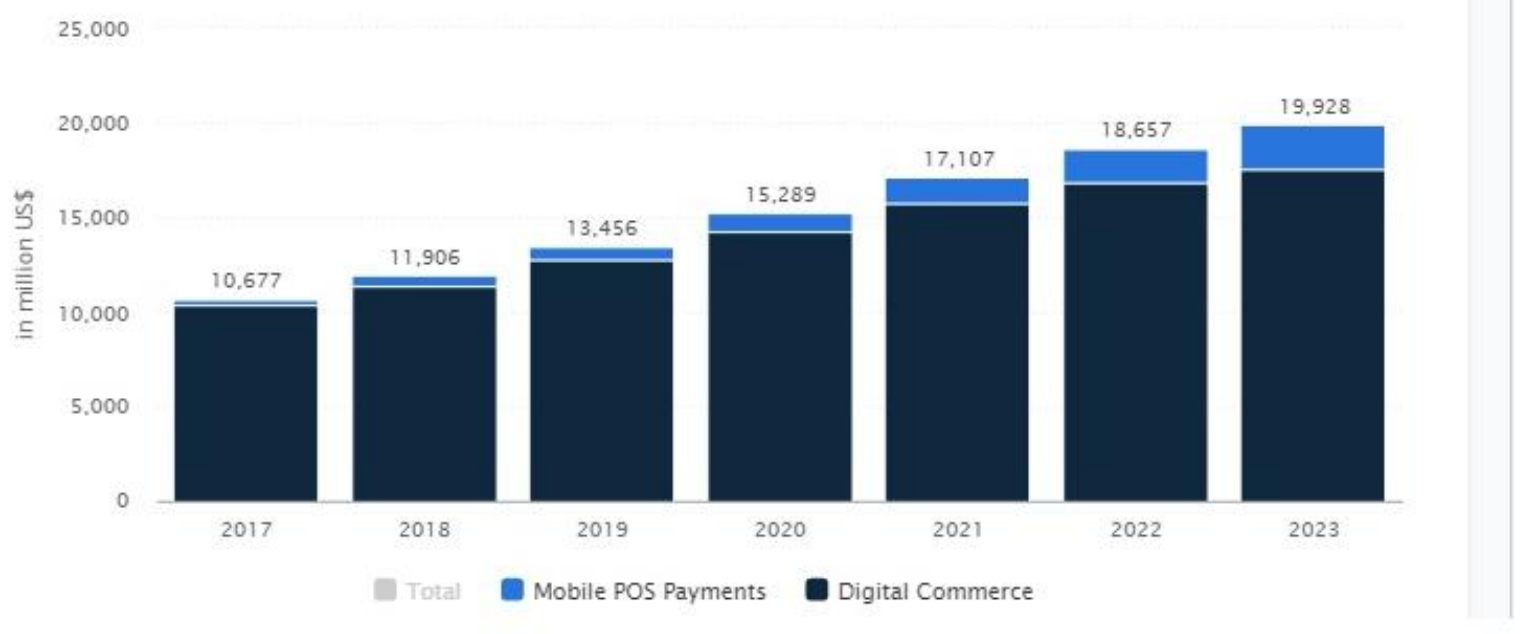

Figure 2. Transaction values of digital payments in Saudi Arabia (Statista, 2019)

\section{Opportunities of E-commerce Business in Saudi Arabia}

A study conducted by Karake-Shalhoub and Al Qasimi (2006) reported that e-commerce has changed the dynamics of retail market and were of the view that Saudi Arabia offers huge potential for e-commerce business. Similar views were shared by Almosa (2011) and said that e-commerce is still untapped in Saudi Arabia and major players in the market globally are eagerly looking out for opportunities for becoming a part of the Saudi Arabia's e-commerce growth story. We concur with these views and it became evident when Amazon acquired Souq.com, a Dubai-based e-commerce giant that boasts of having over 50 million customers. This positioning from Amazon, a global e-commerce leader with the aspirations of becoming a major player in e-commerce business clearly highlights the growing prospects of e-commerce in Saudi Arabia. In direct competition to Amazon, Noon.com was launched in 2017 estimated worth of \$1 billion. 


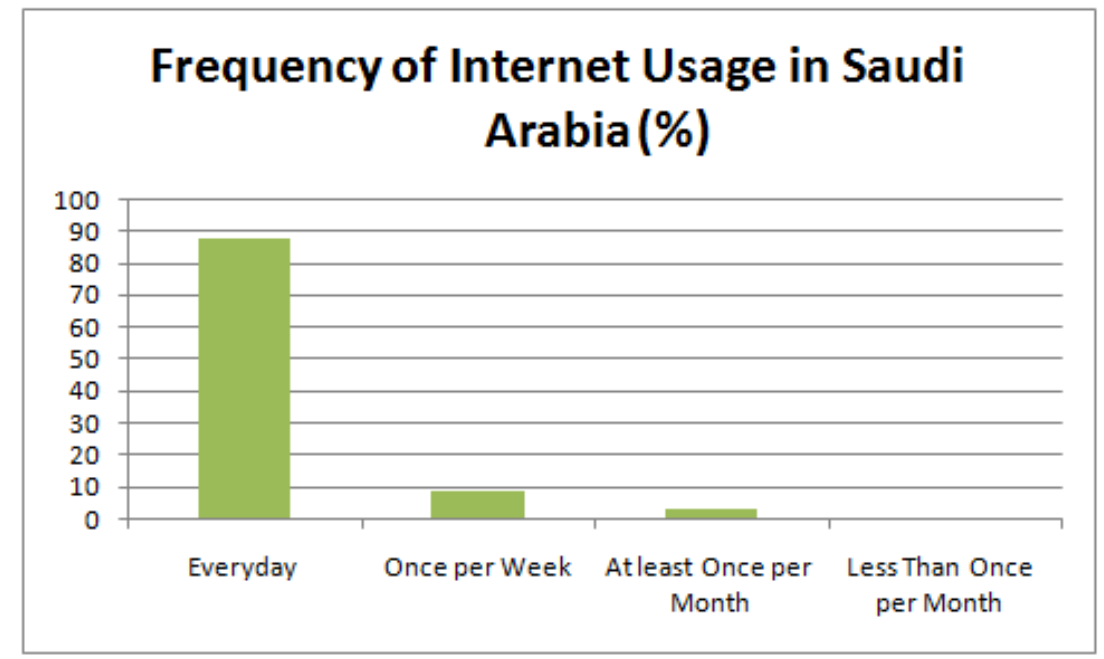

Figure 3. Frequency of internet usage in Saudi Arabia (Statista, 2019)

A study conducted by Statista (2019) about the frequency of Internet usage by users in Saudi Arabia and the type of e-commerce activities revealed a promising future of e-commerce business. The conclusion of the study is shown in Figure 3 and Figure 4. it is evident from Fig. 3 that Internet users are active every day and Fig. 4 shows $88 \%$ of the users searched for product or service online and $47 \%$ bought a product or service online. Based on these facts and studies, it can be safely concluded that e-commerce business in Saudi Arabia is set for achieving new heights and a huge opportunity is available to be seized from the organisations.

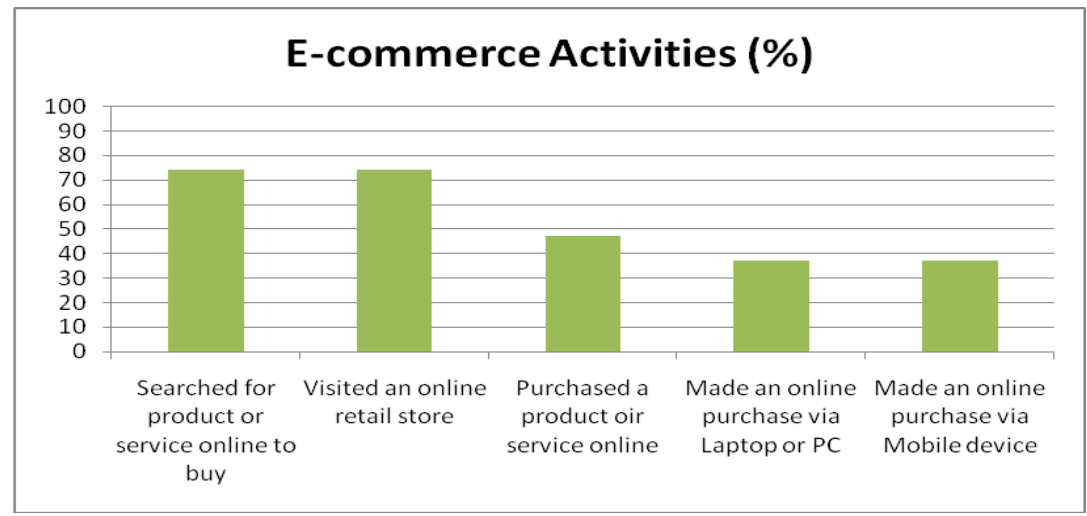

Figure 4. E-commerce activities in Saudi Arabia (Statista, 2019)

\section{Impact of Big Data on For-Profit E-commerce Organisations in Saudi Arabia}

From the previous section it is clear that e-commerce is set to have bright future in Saudi Arabia. We share the concerns of Constantiou and Kallinikos (2015) who argued that traditional databases are not capable of handling huge amount of data that are continuously coming out of business transactions, social media, internal information, external information, etc. Also, the information from external sources are heterogeneous that could be structured, unstructured or semi-structured. Raguseo and Vitari (2018) also expressed serious doubts about continuing with traditional databases for capturing, processing and interpreting data. Mikalef et al. (2018) conducted a study on the importance of capturing and processing massive data emanating on the Internet with reference to e-commerce organisations. After conducting detailed study, they concluded that using information from social media and other external sources helps the e-commerce organisations understand the individual consumer behaviour. They added that 
this information is vital in gaining competitive advantage over the peers as this data can be used to offer customised products, dynamic pricing and also use for targeting the right customer with specific products. Hence, some of the important points that can be inferred are; a) massive amount of data is available about the customers b) traditional databases are not capable enough to handle such large data c) processing the information about consumer behaviour is vital for gaining competitive advantage. In this context, many experts such as Barlow (2013), Chen et al. (2014) and Raguseo and Vitari (2018) have advocated for the use of Big Data technology that specifically designed to handle large heterogeneous data with high speed and effective data security framework.

Barlow (2013) identified the impact areas of Big Data in e-commerce organisations and Figure 5 illustrates those key areas.

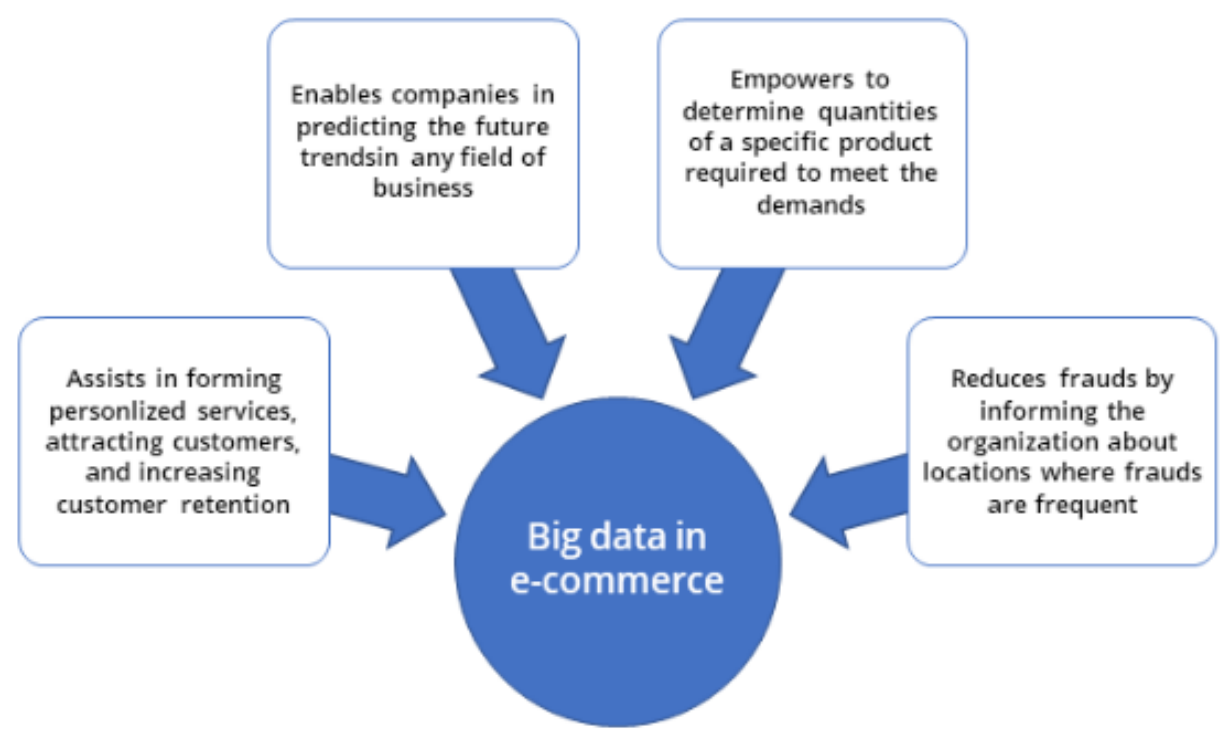

Figure 5. Impact areas of big data in e-commerce (Barlow, 2013)

It can be understood from Figure 5 that Big Data plays a key role in offering personalised services resulting in increased customer retention. Big Data helps in forecasting future trends and thus helping in efficient inventory management. Big Data alerts any fraudulent activities by capturing key information such as location details. Big Data streamlines the online digital payments and customers can have easy payment facilities that is secured and trusted.

Mikalef et al. (2018) carried out a study to determine the importance of predictive analytics offered by Big Data technology. They concluded that predictive analytics plays a pivotal role in forecasting, marketing, customer service, product offers and fraud detection. The findings of the study are shown in Fig.6 that clearly shows a significant enhancement in e-commerce operations and marketing. 


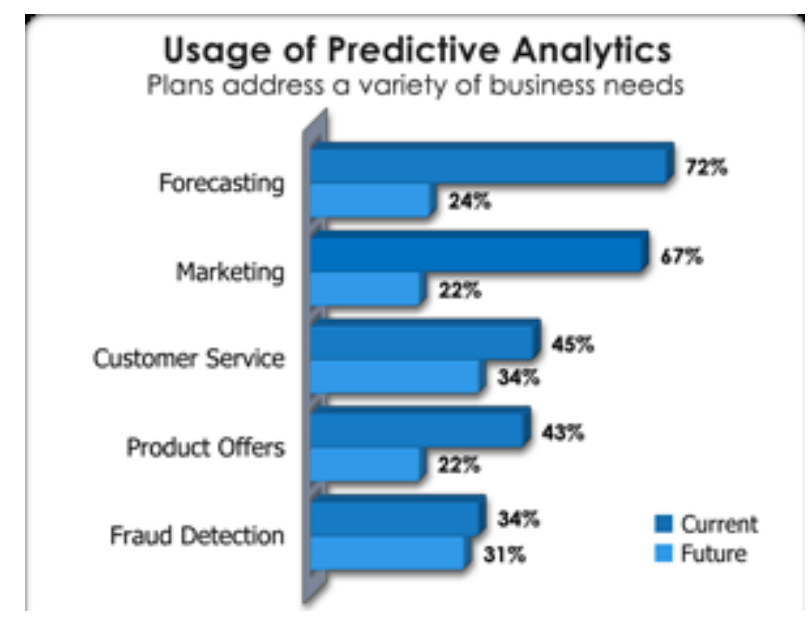

Figure 6. Predictive analytics in e-commerce organisations (Mikalef et al., 2018)

\section{Research Problem}

Based on the literature research, it has been established that Big Data has the ability to overcome the drawbacks of traditional database systems. It is capable of handling large amount of data that can be used in predictive analytics for forecasting, marketing, product customisation, fraud detection and customer service. Using qualitative interviews this research aims to highlight the impact of Big Data on for-profit e-commerce organisation in Saudi Arabia by gathering information about challenges and opportunities through interviews.

\section{Research Method}

Kvale (2015) suggested using qualitative research approach when the research context is complex and possibility of multiple truths is high. As this research adoptability of latest technology Big Data in Saudi e-commerce organisations, it becomes highly relevant to understand the positioning of the companies and the challenges faced by them in making use of Big Data. Hence, to unveil any hidden truths that could be easily missed out in quantitative research approach, this research uses qualitative approach. Participants were selected using criterion and snowball sampling. All the participants are from Saudi Arabia and highly experienced skilled professionals in the field of e-commerce, marketing, technology and management. The combined experience of all the participants exceeds 150 years and therefore, considered as representation of the mass. All relevant ethical guidelines were followed throughout this research and no sensitive data, such as DOB, address, contact numbers, age, etc., was collected as that is not relevant to this research. Table 1 shows the profile of the participants.

Table 1. Profile of participants

\begin{tabular}{llll}
\hline Participant & Designation & $\begin{array}{l}\text { Number } \\
\text { Participants }\end{array}$ & $\begin{array}{l}\text { of } \\
\text { Experience } \\
\text { E-Commerce, Big Data, } \\
\text { Consumer Behaviour and } \\
\text { Marketing }\end{array}$ \\
\hline P1 & Head of Operations & 1 & 17 years \\
\hline P2 & Director of Marketing & 1 & 25 years \\
\hline P3 & Senior Technology Consultant & 1 & 18 years \\
\hline P4 & $\begin{array}{l}\text { Consumer Behaviour and } \\
\text { Integrated Marketing Expert }\end{array}$ & 1 & 17 years \\
\hline P5 & Director of Technology & 1 & 19 years \\
\hline P6 & E-commerce Expert & 1 & 18 years \\
\hline P7 & Social Media Expert & 1 & 16 years \\
\hline P8 & Director of Finance & 1 & 21 ears \\
\hline
\end{tabular}




\section{Results and Analysis}

To make it easy to understand, the results and analysis is classified into three categories; i) Current situation of E-commerce industry in Saudi Arabia ii) Impact of Big Data on e-commerce organisations in Saudi Arabia and iii) Challenges and Future of e-commerce industry in Saudi Arabia. Several questions were put forward to all the participants that falls in to one of the above categories to gather all the required information to derive the findings logically by using multiple sources of evidence.

\subsection{Current Situation of E-commerce Industry in Saudi Arabia}

In order to find out the current scenario of e-commerce industry in Saudi Arabia, the participants were asked to explain the current situation. The findings from literature research suggested a promising current and future situation for e-commerce industry. The responses are shown in Fig. 7. The general response from the participants was on those same lines and expressed happiness about the prevailing situation in e-commerce sector. P2 suggested that the government is taking the right steps in making the Internet accessible to people at a low cost. P4 expressed similar views and said that Internet and smartphones have changed the way the business is conducted and expressed it's the right time to be in e-commerce business. There a general consensus about lot of room left for improvements to boost Internet penetration and increasing consumer confidence in buying products or services online. P6 was a bit critical about the pace of growth in e-commerce industry compared to other emerging and developed countries around the globe. P6 further added that cultural influences may be the reason behind lagging in technology in e-commerce, however, was positive that a lot has changed and Saudi Arabia is embracing new technologies at a much faster pace than before.

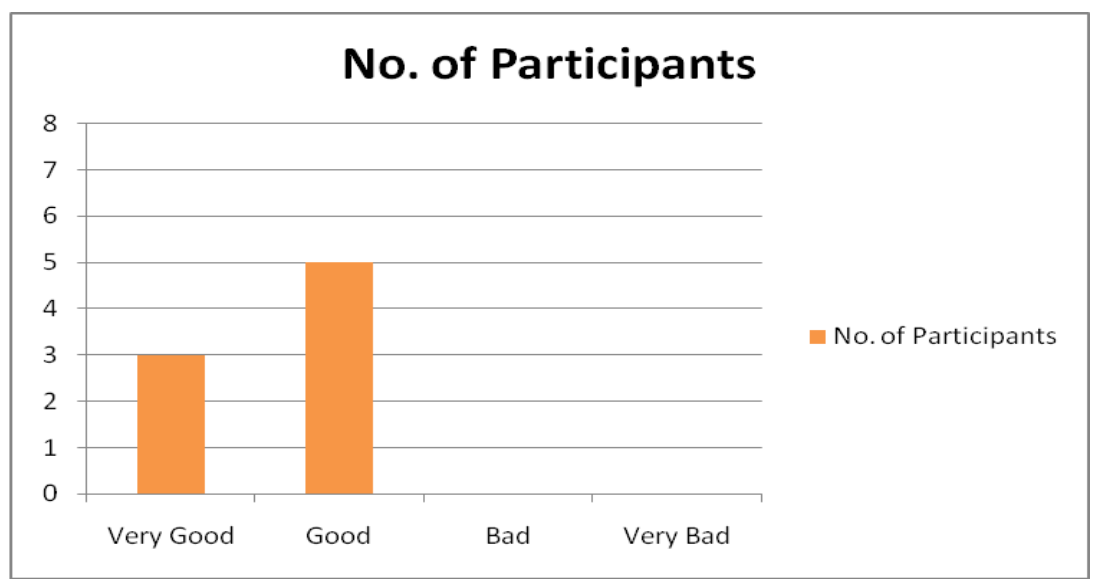

Figure 7. Current situation of e-commerce industry in Saudi Arabia

P7 suggested that social media is gaining huge momentum in Saudi Arabia and attributed that to the higher youth population. This validates the findings of Barlow (2013) who suggested the massive penetration rate of social media in Saudi Arabia. The penetration rate of the study is shown in Fig. 8. P4 suggested that with the acquisition of souk.com by Amazon has changed the dynamics of e-commerce as they are the leading online retailer globally. P8 was of the view that organisations are hesitant to upgrade to latest technologies due to cost involved and most importantly, uncertainty due to lack of research that is specific to Saudi Arabia. P8 further expressed that due to different cultural backgrounds in Saudi Arabia, e-commerce organisations take some time to implement new technologies. Similar views were found out through literature research that said fear of risk and fear of failure as the barriers in e-commerce industry. 


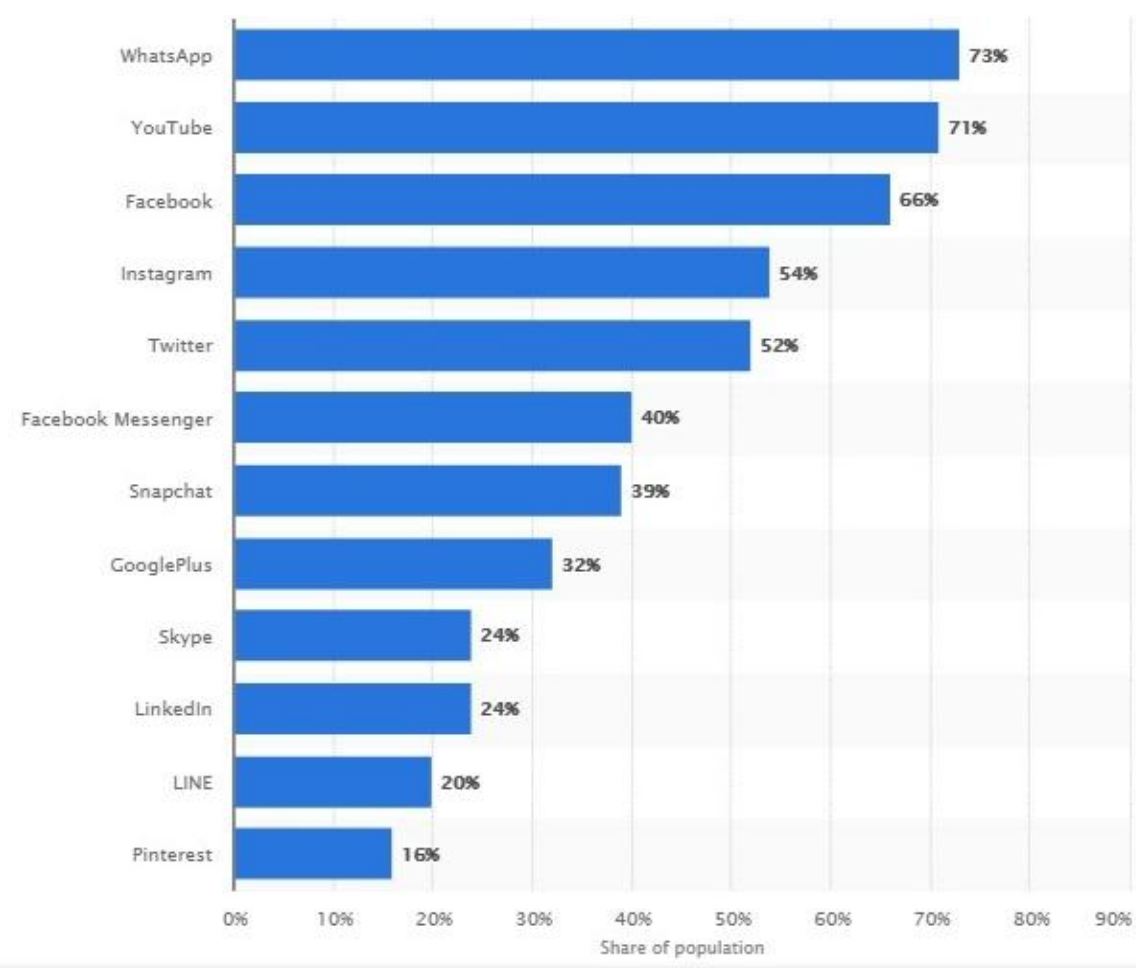

Figure 8. Penetration of leading social networks in Saudi Arabia

\subsection{Impact of Big Data on E-commerce Organisations in Saudi Arabia}

Participants were asked to express their views on impact of Big Data in e-commerce industry in Saudi Arabia. No participants were new to Big Data. They all were fully aware of the potential of Big Data in e-commerce industry. Most of the participants hold positive views on Big Data. The responses are shown in Fig. 9. However, P8 was a bit sceptical about investing in massive data capturing, processing and interpreting as the returns are not conclusive yet. P8 further added that the type of data emanating somewhere else in the world would dramatically differ from Saudi Arabia. Hence, to analyse the impact on e-commerce would need some more time. Contrastingly, P2 was upbeat about Big Data and said the results in the company he works for has already started providing better insights about consumer behaviour. P2 said that his company has been using Big Data since 18 months and they have been able to tap into their target market much more effectively. P1 also shared similar views and said that there are some challenges when dealing with Big Data due to lack of professionals.

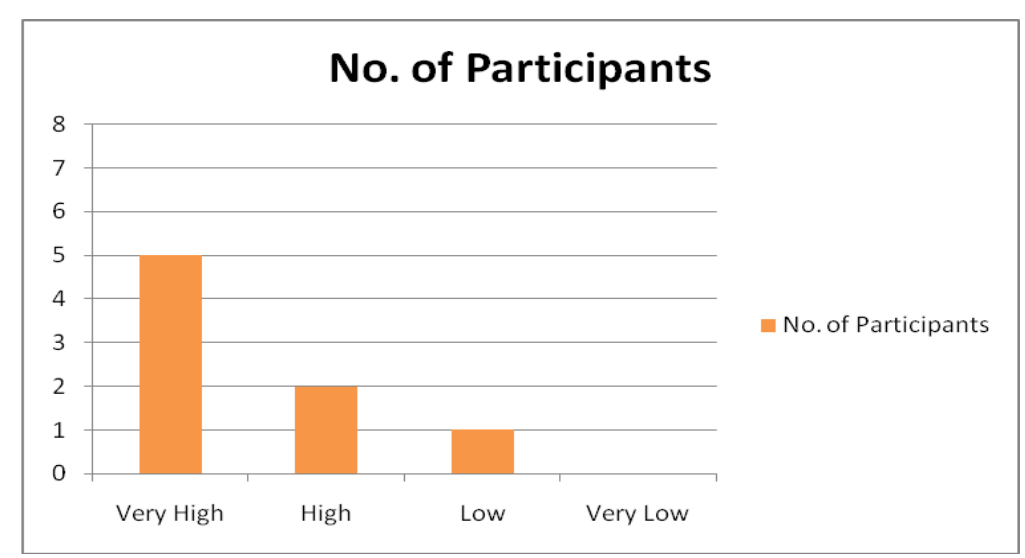

Figure 9. Impact of big data on e-commerce organisations in Saudi Arabia 
P5 suggested that the Big Data technology is impressive and suggested as the future of e-commerce. P3 suggested that traditional databases could be used for some backend processes; however, e-commerce companies cannot ignore the valuable data available on the Internet about the customers. P7 suggested that e-commerce companies have started to realise the power of social media. Although some companies are taking smaller steps, P7 argued that social media presence is critical to get connected with its customers. P4 expressed that the key barrier for e-commerce industry is the trust. People are still hesitant to buy online and make payments online for the products or services that they have not seen. It needs to evolve to make the most out of the latest technologies. P6 suggested that the inventory management has been much more effective after the implementation of Big Data in her company. The predictive analytics has been really good in forecasting and understanding consumer buying patterns.

\subsection{Challenges and Future of E-commerce Industry in Saudi Arabia}

All the participants expressed positively about the future of Big Data in e-commerce industry. The responses are shown in Fig. 10. P8 was sceptical about impact of Big Data in the current situation; however, he was positive that it would be made more relevant in future with more professionals available to manage the technology much better.

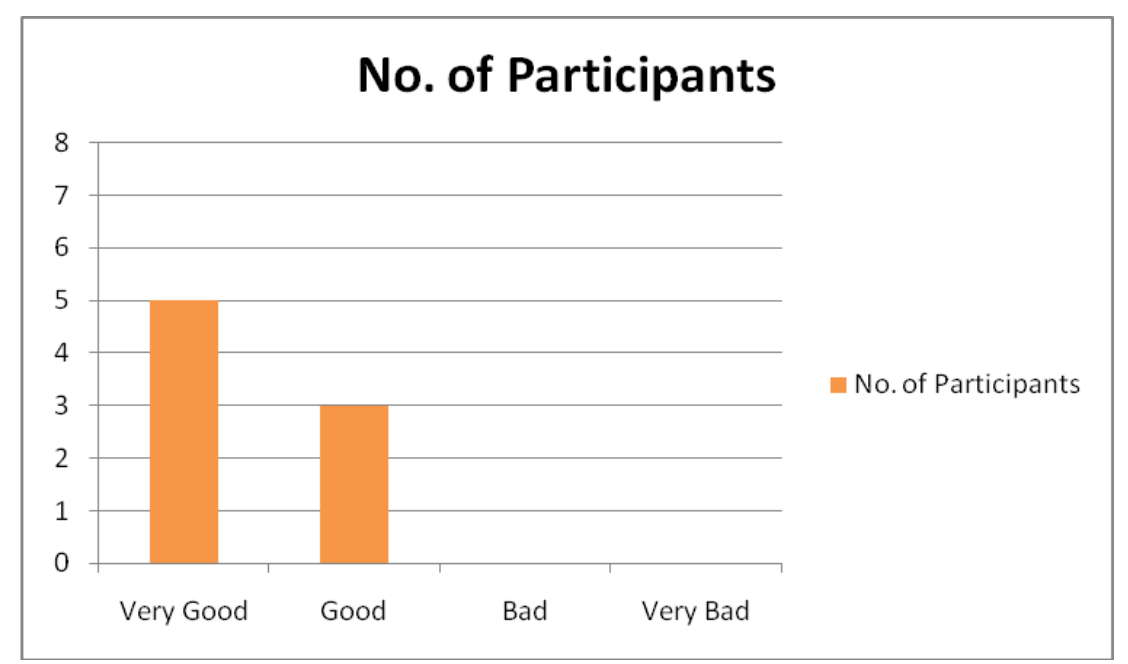

Figure 10. Challenges and future of e-commerce industry in Saudi Arabia

P2 suggested that marketing would be much more effective and whoever has the ability to manage the data better will have an upper hand in the e-commerce industry. P3 suggested that the prospects looks bright for Big Data, however, security concerns must be adequately addresses and resolved for it to stay sustainable. Security concerns about data privacy were expressed by many as the key challenge facing the industry. Therefore, Big Data should be able to provide adequate security to achieve higher levels of data security.

\section{Recommendations and Conclusion}

The primary objective of this research was to fill the gap in research by critically evaluating the rapidly growing Big Data technology specific to e-commerce organisations in Saudi Arabia. Organisations in Saudi Arabia are hesitant to simply implement technologies that have worked for Western countries, highlighting cultural differences. That seems to be a valid point, hence, this research aimed at filling that research gap to an extent. This is an information era and information is seen as an asset by companies and this is especially true for e-commerce companies. Massive data arriving from various sources such as internal, external, social media, etc., are bombarding the doors of companies and they cannot be ignored. This research has found out that traditional databases are not capable enough of handling such enormous data. Big Data is a promising technology for e-commerce organisations in Saudi Arabia. E-commerce companies in Saudi Arabia are recommended to use the Big Data technology to gain invaluable insight into consumer behaviour so that customised products and services can be provided in real time. Further research is needed to address the security concerns of Big Data and we urge the research community to carry out researches that are specific to Saudi Arabia. Some of the recommended further research includes Security threats in Big Data, Cloud Computing and Knowledge Management Systems. 


\section{References}

Ahmad, I., \& Agrawal, A. M. (2012). An Empirical Study of Problems in Implementation of Electronic Commerce in Kingdom of Saudi Arabia. International Journal of Business and Management, 7(15), 70-80.

Akter, S., \& Wamba, S. F. (2016). Big data analytics in e-Commerce: a systematic review and agenda for future research. Electronic Markets, 26, 173-194.

AlGhamdi, R., Drew, S., \& Alfarraj, O. (2011). Issues Influencing Saudi Customers' Decisions to Purchase from Online Retailers in the KSA: A Qualitative Analysis. European Journal of Scientific Research, 4, 580-593.

Alkhunaizan, A., \& Love, S. (2013). Effect of demography on mobile commerce frequency of actual use in Saudi Arabia. Advances in Intelligent Systems and Computing, 206, 125-131.

Almosa, M. (2011). Profiling E-buyers in Saudi Arabia : Saudi Arabia as A Promising Developing Country. Cross-cultural Communication, 7(2), 92-100.

Al-Shohaib, K., Al-Kandari, A., \& Abdulrahim, M. (2009). Internet Adoption by Saudi Public Relations Professionals. Journal of Communication Management, 13(1), 21-36.

Barlow, M. (2013). Real-Time Big Data Analytics: Emerging Architecture (1st ed.). Sebastopol: O’Reilly Media.

Chen, M., Mao, S., Zhang, Y., \& Leung, V. C. (2014). Big Data Related Technologies, Challenges and Future Prospects (1st ed.). London: Springer.

Constantiou, I. D., \& Kallinikos, J. (2015). New Games, New Rules: Big Data and the Changing Context of Strategy. Journal of Information Technology, 30, 44-57.

Karake-Shalhoub, Z., \& Al Qasimi, L. (2006). The diffusion of e-commerce in developing economies: a resource-based approach. London: Edward Elgar Publishing.

Kvale, S. (2015). InterViews: learning the craft of qualitative research interviewing (3rd ed.). Thousand Oaks: Sage Publications Linthicum.

Manyika, J., Chui, M., Brown, B., Bughin, J., Dobbs, R., Roxburgh, C., \& Byers, A. H. (2011). Big data: The next frontier for innovation, competition, and productivity. Washington: McKinsey Global Institute.

Mikalef, P., Pappas, I.O., Krogstie, J., \& Giannakos, M. (2018). Big data analytics capabilities: A systematic literature review and research agenda. Information Systems and e-Business Management, 16, 547-578.

Raguseo, E., \& Vitari, C. (2018). Investments in big data analytics and firm performance: An empirical investigation of direct and mediating effects. International Journal of Production Research, 1-16.

Statista. (2019). Saudi Arabia - Statistics and Facts. [online] Retrieved12 Oct 2019, from https://www.statista.com/topics/1630/saudi-arabia/

Wamba, S. F., Akter, S., Edwards, A., Chopin, G., \& Gnanzou, D. (2015). How 'big data' can make big impact: Findings from a systematic review and a longitudinal case study. International Journal of Production Economics, 165, 234-246. 